\title{
Maternal health: There is cause for optimism
}

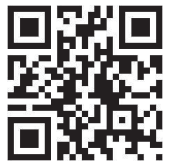

Maternal health is a major health priority for international agencies, the African Union, and the South African Government. ${ }^{[1-3]}$ In 2000, all United Nations (UN) member states agreed to substantial improvements in maternal health, defined by Millenium Development Goal 5 (MDG5), which includes the specific target of reducing maternal mortality by $75 \%$ between 1990 and 2015. ${ }^{[4,5]}$ While many countries are making progress, maternal mortality in South Africa (SA) has significantly increased during this time. ${ }^{[6]}$ Data from the 2007 Community Survey suggest that maternal mortality in SA, rather than showing evidence of reduction, may have quadrupled from 1998 to 2007..$^{[7]}$ The SA National Committee for Confidential Enquiries into Maternal Deaths (NCCEMD) reports, which analyse institutional maternal mortality, have shown an increase in maternal deaths, from the first report in 1998 to the latest triennial report covering the years $2008-2010 .^{[8]}$

HIV infection is the major cause of the large increase in maternal mortality. The national antenatal prevalence of HIV remains at around $30 \%$, and is largely unchanged from 2004. ${ }^{[9]}$ Non-pregnancyrelated infections in HIV-positive women are the single most common cause of maternal mortality, accounting for over $40 \%$ of all maternal deaths. ${ }^{[8]}$ However, even if deaths from HIV/AIDS are removed from the total, maternal mortality would still be higher than expected for a middle-income country with good health infrastructure. ${ }^{[6]}$ For other countries in sub-Saharan Africa with high maternal mortality, resource limitations are a major constraint for healthcare delivery. However, in SA maternity care is free and the per capita health budget is the highest in the region. Avoidable factors, missed opportunities, poor quality of care and the lack of training of front-line healthcare workers have all been found to contribute to maternal deaths from all causes. ${ }^{[8]}$

Despite all of these issues, there is good cause for optimism. SA has the largest antiretroviral treatment (ART) programme in the world, with 2 million people on highly active antiretroviral therapy (HAART) today. ${ }^{[0]}$ Prevention of mother-to-child transmission (PMTCT) has evolved through several major policy changes since the national programme began in 2002, when single-dose nevirapine in labour was the only available treatment. ${ }^{[10]}$ The latest national guidelines from April of this year state that all HIV-positive pregnant women are to start HAART, irrespective of $\mathrm{CD} 4^{+}$count. ${ }^{[1]}$ There are approximately 280000 HIV-positive pregnant women a year, ${ }^{[8]}$ so strategies for rapid scale-up of ART services for pregnant women are in progress. Women not eligible for ongoing HAART, according to the national adult guidelines (CD4 ${ }^{+}$ count $>350$ and stage 1 or 2 disease), are to discontinue HAART after breastfeeding is complete. The Western Cape, as yet alone amongst the provinces, has made the decision that all pregnant women are eligible for lifelong HAART. ${ }^{[12]}$ PMTCT has undergone radical change since its minimalist beginnings just over 10 years ago.

A further cause for optimism is that maternal mortality may at last be falling. The maternal mortality ratio in 1990, based on government estimates, was $150 / 100000$ live births ${ }^{[6]} \mathrm{A}$ 75\% reduction from this level gives the MDG5 target for 2015 to be 38/100 000 live births. SA lacks verifiable means of counting maternal deaths, and estimates of overall maternal mortality for 2007/2008 have ranged from 310 to $>700 / 100000$ live births. ${ }^{[7]}$ While the national target for MDG5 may seem unachievable, there is evidence of a significant recent reduction in maternal mortality. The NCCEMD has just released an interim report for 2011. ${ }^{[13]}$ Analysis is restricted to deaths within a health facility, so deaths at home are not included in the total.
The latest triennial report covering the years 2008 - 2010, showed an institutional maternal mortality ratio of $176 / 100000$ live births overall, and 430/100 000 live births for HIV-positive women. ${ }^{[8]}$

The 2011 data has revealed a significant (13\%) reduction in the maternal mortality ratio, to $153 / 100000$ live births overall. This reduction is even greater for HIV-positive women, showing a maternal mortality ratio of 354/100 000 live births (17.7\% reduction). Deaths from non-pregnancy related infections remain the highest single category, but showed an astounding $28 \%$ reduction in mortality amongst HIV-positive women. There is good reason to believe that this decrease is the first sign of a downward trend, rather than an anomalous result. All provinces and healthcare facilities at all levels of care showed a reduction in deaths from non-pregnancy related infections. Of note, in April 2010 the $\mathrm{CD}^{+}$count threshold for initiation of HAART for pregnant women increased from 200 to 350; the scale-up of ART may well be the significant factor resulting in a lower risk of opportunistic infections and consequent maternal death. Additionally, access to ART for pregnant women had been prioritised. The 2010 national ART guidelines emphasised that pregnant women needed fast-tracking for HAART. ${ }^{[14]}$ The NCCEMD report for 2004 - 2007, published in 2011, stated that all maternity clinics must provide HAART on site, to prevent avoidable delays that were costing women their lives. ${ }^{[15]}$

In addition, there is now an explicit recognition that the health of HIV-positive mothers is essential for the wellbeing of their infants. PMTCT services initially had a single goal, to prevent vertical transmission. In 2002, the national roll-out was forced on the Department of Health (DoH) by a court order; active intervention was then available to prevent HIV transmission to babies, but their mothers were denied all access to treatment that was essential to keep them alive. ${ }^{[10]}$ The DoH currently has a strong commitment to strengthening and expanding ART programmes. The widening of eligibility criteria for HAART for pregnant women in 2010 was a clear acknowledgement that healthy mothers are essential for child health and wellbeing. Internationally, the Joint United Nations Programme on HIV/AIDS (UNAIDS) 'Global Plan Towards the Elimination of New HIV Infections in Children by 2015 and Keeping Their Mothers Alive' emphasises that child and maternal health are inextricably linked, and that both are part of the same goal. ${ }^{[1]}$

Maternal health needs to be seen in a broader context than preventing maternal mortality. MDG5 also contains targets relating to universal access to reproductive health. SA is doing well on many of these indicators. Over $97 \%$ of pregnant women access antenatal care, and $>90 \%$ deliver in a health facility and are attended by trained healthcare workers. ${ }^{[16]}$ HIV-prevention services and easy access to contraception are also prioritised, as is the need to integrate health services for women, newborns and children. Prevention of unwanted pregnancy in adolescents is a specific focus, recognising that this is a major contributor to maternal and neonatal mortality. Contraception for women with medical problems, which may become life threatening in pregnancy, also needs urgent attention. The 2011 Interim Report also noted an increase in maternal deaths due to medical and surgical disorders. ${ }^{[13]}$ This emphasises that it is not just in the context of women's health services that issues such as contraception are relevant. It is equally important in cardiac or other medical clinics, and in medical wards: physicians need to be aware that ensuring reliable contraception may be their most important contribution to saving the lives of women of reproductive age who are under their care. 
Screening for tuberculosis (TB) also needs to be integrated with maternity care ${ }^{[8]} \mathrm{TB}$ is the most common opportunistic infection causing maternal mortality in SA, with deaths occurring both antenatally and postpartum. Midwives need to perform symptom screening for TB at each antenatal visit, and ensure that all women who screen positive are investigated for TB. Services that are traditionally performed by different healthcare workers in separate clinics are therefore being brought together in a single consultation. This type of holistic approach is a simple intervention, but one that can potentially save women's lives.

The MDGs have focused attention on health-service delivery in terms of goal-oriented planning, strategies to achieve targets, and accountability for their outcome. While there is cause for optimism in terms of improving maternal health, there is still much to be achieved. Maternal deaths are an avoidable tragedy, and their prevention an urgent priority. Maternal health is a priority at all levels: for women themselves, their children, partners and extended families, and for society as a whole. Research in this field is therefore of utmost importance. This issue of the SAMJ contains two research papers that address these issues. ${ }^{[17,18]}$ They address health service delivery from different viewpoints, but with the single aim of optimising outcomes for women with complicated pregnancies.

\section{Rosie Burton}

Khayelitsha District Hospital, Cape Town and Obstetric Infectious Diseases Clinic, Groote Schuur Hospital, Cape Town, South Africa

Corresponding author: R Burton (rosie@polka.co.za)

1. UNAIDS. Countdown to Zero. Global Plan Towards the Elimination of New HIV Infections among Children by 2015 and Keeping Their Mothers Alive. Geneva: UNAIDS 2011. http://www.unaids.org/ en/media/unaids/contentassets/documents/unaidspublication/2011/20110609_jc2137_global-planelimination-hiv-children_en.pdf (accessed 28 June 2013).
2. Campaign on Accelerated Reduction of Maternal and Child Mortality in Africa. CAMMRA Report 2013. Johannesburg: UNPFA, 2013. http://esaro.unfpa.org/webdav/site/africa/users/Lbarnes/public/ Carmma\%20report\%202013.pdf (accessed 27 June 2013).

3. Department of Health. South Africa's National Strategic Plan for a Campaign on Accelerated Reduction of Maternal and Child Mortality in Africa (CARMMA). Pretoria: DoH, 2012. http://www.doh.gov.za/ docs/stratdocs/2012/carmma.pdf (accessed 1 July 2013).

4. MDG Africa Steering Group Achieving the Millennium Development Goals in Africa MDG Africa Steering Group. Achieving the Millennium Development Goals in Africa,
Recommendations of the MDG Africa Steering Group, June 2008. Geveva: UN Department of Public Relations, 2008. http://www.mdgafrica.org/pdf (accessed 1 July 2013).

Relations, 2008. http://www.mdgafrica.org/pdf (accessed 1 July 2013).
UN Economic Commission for Africa. MDG Report 2013: Assessing Progress in Africa Towards the UN Economic Commission for Africa. MDG Report 2013: Assessing Progress in Africa Towards the
Millenium Development Goals. Geneva: UNECA, 2013. http://www.undp.org/content/dam/undp/ library/MDG/english/MDG\%20Regional\%20Reports/Africa/MDG\%20report\%202013\%20summary EN.pdf (accessed 1 July 2013)

6. Human Rights Watch. 'Stop Making Excuses'. Accountability for Maternal Health Care in South Africa. New York: Humans Rights Watch, 2011. http://www.hrw.org/sites/default/files/reports/ sawrd0811webwcover.pdf (accessed 28 June 2013).

Garenne M, McCaa R, Nacro K. Maternal mortality in South Africa: An update from the 2007 Community Survey. J Popul Res 2011;8(1):89-101. [http://dx.doi.org/10.1007/s12546-010-9037-y]

8. National Committee on Confidential Enquiries into Maternal Deaths. Saving Mothers 2008-2010: Fifth report on the Confidential Enquiries into Maternal Deaths in South Africa. Pretoria: DoH, 2012 http:/

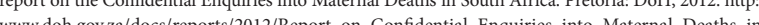
www.doh.gov.za/docs/reports/2012/Repot_.

- The 2011 National Antenatal Sentinel HIV \& Syphilis Prevalence Survey in South Africa. Pretoria: DoH, 2013. http://www.doh.gov.za/docs/presentations/2013/Antenatal_Sentinel_ survey_Report2012_final.pdf (accessed 3 July 2013).

10. Barron P. Pillay Y, Doherty T, et al. Eliminating mother to child transmission in South Africa Bull World Health Organ 2013;91(1):70-74. [http://dx.doi.org/10.2471/BLT.12.106807]

11. Department of Health. Clinical Guidelines for the Management of HIV \& AIDS in Adults and Adolescents. Pretoria: DoH, 2010. http://www.fidssa.co.za/Guidelines/2010_Adult_ART_Guidelines.pdf (accessed 3 July 2013).

12. Western Cape Department of Health. PMTCT Clinical Guidelines Update. Cape Town: WCDoH, 2013 3. National Committee on Confidential Enquiries into Maternal Deaths. Ninth Interim Report in the Confidential Enquiries into Maternal Deaths in South Africa. Pretoria: DoH, 2013.

14. Department of Health. The South African Antiretroviral Treatment Guidelines 2013. Pretoria, DoH, 2013. http://www.sahivsoc.org/upload/documents/2013\%20ART\%20Treatment\%20Guidelines\%20 Final\%2025\%20March\%202013\%20corrected.pdf (accessed 2 July 2013).

15. National Committee on Confidential Enquiries into Maternal Deaths. Saving Mothers 2005-2007: Fourth report on the Confidential Enquiries into Maternal Deaths in South Africa. Pretoria, DoH, 2009. http://www.doh.gov.za/docs/reports/2011/saving b.pdf (accessed 3 July 2013.)

16. South African Government. Millenium Development Goals: Country Report 2010. Pretoria: Government South African Government. Millenium Development Goals: Country Report 2010. Pretoria: Governmen
Press, 2010. http://www.statssa.gov.za/news_archive/Docs/MDGR_2010.pdf (accessed 28 June 2013). Press, 2010. http://www.statssa.gov.za/news_archive/Docs/MDGR_2010.pdf (accessed 28 June 2013). Ngene NC, Moodley J, Songca P, et al. Maternal and fetal outcomes of HIV-infected and non-infected
pregnant women admitted to two intensive care units in Pietermaritzburg, South Africa. S Afr Med J pregnant women admitted to two intensive care units in Pietermaritzburg, South Africa. S Afr Med 2013;103(8):543-548. [http://dx.doi.org/10.7196/SAMJ.6590]

18. Schoon MG. Impact of inter-facility transport on maternal mortality in the Free State Province. S Afr Med J 2013;103(8):534-537. [http://dx.doi.org/10.7196/SAMJ.6828]

S Afr Med J 2013;103(8):520-521. DOI:10.7196/SAMJ.7237

\section{This month in the $S A M J .$.}

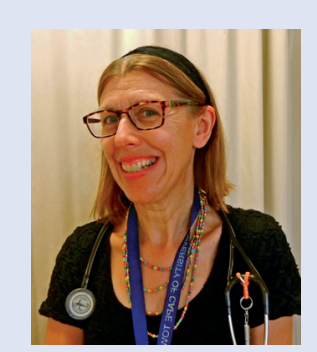

Rosie Burton* graduated from the Royal Free Hospital Medical School, London. She is doubly qualified as an obstetrician and physician and, as the latter, has super-specialised in infectious diseases. She is currently consultant physician and infectious diseases specialist at Khayelitsha District Hospital, with a consulting role in the Department of Obstetrics at Groote Schuur Hospital. As an obstetric physician, her major interest is in the medical conditions, and infectious diseases, of pregnant women, and their impact on maternal morbidity and mortality. She is a strong advocate for specialist physicians to be more involved in obstetric practice.

*Burton R. Maternal health: There is cause for optimism. S Afr Med J 2013;103(8):520-521. [http://dx.doi.org/10.7196/SAMJ.7237]

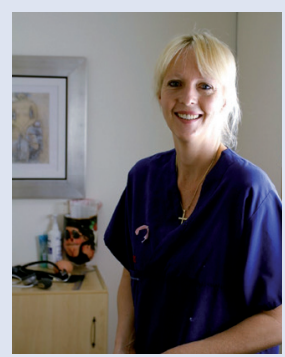

Carol-Ann Benn* graduated from the University of the Witwatersrand in 1991, becoming a Fellow of the College of Surgeons of South Africa (FCS (SA)) in 1998. She is the Head and founder of the Breast Clinics at Johannesburg General and Chris Hani Baragwanath Hospitals, and Head of the premier Gauteng Department of Health Breast Unit at Helen Joseph Hospital. She is National Director of the Netcare Breast Care Centre of Excellence and serves on the Board of Directors of Breast Disease Centres and International Medical Societies in Paris, France and numerous national advisory panels. In 2010 she was the recipient of South Africa's Most influential Women in Business and Government Award (Medical). She is editor of the International Breast Disease Journal.

*Benn C-A. The circle of life. S Afr Med J 2013;103(8):496. [http://dx.doi.org/10.7196/SAMJ.7236] 